Cómo citar este trabajo: Rivera Mateos, M. (2018). Turismo activo, recreación al aire libre y deportes de naturaleza: una lectura geográfica. Boletín de la Asociación de Geógrafos Españoles, 77, 462-492. doi: http://dx.doi.org/10.21138/bage.2548

\title{
Turismo activo, recreación al aire libre y deportes de naturaleza: una lectura geográfica
}

\author{
Active tourism, outdoor recreation and nature sports: \\ a geographical reading
}

\author{
Manuel Rivera Mateos \\ manuel.rivera@uco.es \\ Departamento de Geografía y Ciencias del Territorio \\ Universidad de Córdoba (España)
}

\section{Resumen}

Este artículo realiza una lectura geográfica de los espacios deportivos y recreativo-turísticos de naturaleza, que en las últimas décadas se han convertido en un producto-destino de grandes potencialidades en el mercado turístico de zonas rurales, de montaña o litorales. Se estudian las principales aportaciones de la Geografía en el estudio de los deportes de naturaleza y sus espacios de práctica y las posibilidades, enfoques y planteamientos que esta disciplina puede introducir para una comprensión más integral del turismo deportivo de naturaleza, la mejora de su calidad y sostenibilidad y su consolidación como instrumento de desarrollo local.

Palabras clave: turismo deportivo; recreación al aire libre; territorio; deportes de naturaleza; Geografía.
Abstract
This paper proposes a geographical reading of nature sports and recreational-tourist spaces. Nature sports have gone from being mere recreational physical activities to become a product of great potential in the tourism market in many rural, mountain and coastal areas. In this work the main contributions of Geography in the study of nature sports and its spaces of practice and the possibilities and approaches that this discipline can introduce for a more integral understanding of 
the phenomenon of the natur-based sports tourism, the improvement of its quality and sustainability, and as an instrument of local development.

Key words: sport tourism; outdoor recreation; territory; nature sports; Geography.

\section{Introducción}

Con el desarrollo de la industria del turismo y la creciente concienciación sobre la conservación y disfrute de la naturaleza y las bondades del ejercicio físico para la salud (Kurtzman \& Zauhar, 2005), el turismo deportivo de naturaleza (en adelante TDN) ha visto crecer su popularidad de manera extraordinaria desde finales de los años ochenta (Millington et al., 2001), aún cuando algunos deportes de naturaleza que integran su oferta como el senderismo, el esquí o la escalada, tengan su origen a principios del pasado siglo u otros en los años sesenta y setenta en algunos países desarrollados. Aunque el acercamiento a este fenómeno ha sido tradicionalmente tímido desde algunas ciencias como la Geografía, en las dos últimas décadas se ha percibido un mayor interés por el mismo más allá de su componente recreativa o complementaria de otras actividades turísticas, a medida que se ha ido consolidándose como una tipología turística específica y diferenciada capaz de definir incluso destinos especializados y con lógicas singulares de producción del espacio turístico (Lacosta, 2004). Este interés se debe también a su impacto económico asociado, el atractivo que genera por los valores y representaciones que transmite (contacto con la naturaleza, ecología, bienestar, disfrute del paisaje, acción y aventura, libertad...) y la utilización del deporte como soporte de la promoción e imagen de marca de muchos destinos turísticos (Pigeassou, 2004; Bouchet \& Bouhaouala, 2009).

El TDN, como categoría de turismo deportivo "activo" (De Knop, 1990; Gibson, 2006), integra un conjunto de actividades físico-deportivas, de carácter motriz y de "aventura controlada", que como oferta más o menos mercantilizada y de fuerte orientación lúdico-recreativa, son practicadas durante las vacaciones al aire libre y en contacto con el medio natural, sirviéndose básicamente de los recursos que ofrece éste y suponiendo un cierto factor de riesgo, esfuerzo físico y/o destreza para sus practicantes. Presentan, asimismo, una gran heterogeneidad y un campo casi ilimitado de modalidades por la diversidad de recursos y entornos naturales que les pueden servir de soporte, sus necesidades diferentes de equipamiento deportivo y sus niveles de riesgo, tecnificación y capacidad o preparación física de los usuarios, así como de técnicas y tipos de práctica empleadas, que conforman distintas "culturas o subculturas deportivas" (Augustin, 2011). A esto se suma la fuerte segmentación de los deportes de naturaleza tradicionales en múltiples derivaciones y adaptaciones, como es el caso del esquí y el alpinismo, que han derivado en más de una veintena de disciplinas, pudiéndose clasificar según escenarios de práctica en tres grupos: deportes terrestres (senderismo, rutas ecuestres, alpinismo y montañismo, bicicleta de montaña, 
espeleología, etc.); deportes aéreos (ala delta, parapente, globo aerostático...) y acuáticos (descenso de aguas bravas, piragüismo, buceo, surf, vela...).

En España y otros países hispanohablantes se ha impuesto el concepto de "turismo activo" para referirse a estas actividades (Rivera, 2015b), aunque de manera impropia, ya que éste es similar o casi sinónimo del de "vacaciones activas" (activity holidays), definición amplia y genérica que incluye un universo muy variado de actividades que van más allá de los deportes de naturaleza y no motorizados, tanto de índole recreativa al aire libre (outdoor recreation) como de carácter educativo (Brown, 2009), deportivo o de aventura (adventure holidays, outdoor adventure activities), aunque con el denominador común de la búsqueda de unas vacaciones dinámicas, de carácter motriz e interactivo, en las que el turista puede convertirse en sujeto activo y protagonista de la experiencia viajera, no contento con "ver" sino prefiriendo "hacer"; "megatendencia turística" que viene detectándose en algunos países desarrollados desde principios de los años ochenta (Bell et al., 2007).

En realidad, las actividades que integran el TDN no institucionalizadas ni convencionales, sin sujeción a reglas deportivas codificadas o estandarizadas, autoorganizadas, no competitivas y de práctica frecuentemente "libre", son más asimilables a los juegos recreativos y no pueden ser consideradas como deportes en el sentido clásico del término, sino más propiamente como actividades de ocio y turismo deportivo (Gammon \& Robinson, 2003; Parlebas, 1999), inscribibles como nueva modalidad turística en el contexto de la recreación al aire libre, que integra a su vez numerosas y heterogéneas actividades, entre las que destacan los deportes de naturaleza (outdoor sports) y aquellos otros deportes al aire libre que implican mayor riesgo y retos físicos para los usuarios (rafting, escalada, etc.), denominados deportes de aventura (adventure recreation). Deportes o prácticas al aire libre, de naturaleza (Bessy \& Mouton, 2004), nuevas actividades de ocio deportivas (Dienot \& Theiller, 1999), deportes californianos (Pociello, 1999), deportes extremos y de aventura (Buckley, 2006), deportes outdoor (Bourdeau et al., 2004), deportes de deslizamiento (Loret, 1995), actividades lúdico-deportivas (Augustin, 2000), etc. son algunas de las numerosas denominaciones utilizadas para calificar estas actividades, que ya de por sí denotan su gran complejidad y variedad y las diferentes formas, modalidades, prácticas, experiencias, evoluciones e implicaciones espaciales, según diferentes escalas y contextos, a las que dan lugar.

El desarrollo de éstas es consecuencia de la diversificación y extensificación en las sociedades urbanas contemporáneas de los modelos deportivos autoorganizados, no competitivos e individualizados, conexionados con el turismo y el ocio, de carácter hedonista y alternativos a los deportes-espectáculo y de masas (Augustin, 2000; Chang \& Gibson, 2011). Pero también de otros muchos factores como el aumento del tiempo de ocio, el mayor poder adquisitivo de los practicantes en países desarrollados, la pérdida de interés por los deportes tradicionales, federados 
y reglados, su mayor accesibilidad para públicos amplios por la mejora de la movilidad y el no requerimiento de especiales condiciones físicas, el auge del imaginario de la aventura deportiva, la mercantilización de las vacaciones deportivas (Corneloup, 2005), la atracción por el medio natural como soporte y cualificación de estas actividades (Bourdeau, 2003) y la búsqueda de cierta diferenciación social a través del turismo deportivo (Giard, 1997). Todos estos factores ponen en evidencia el carácter postmoderno de estas prácticas (Corneloup, 2011) en el marco de unas relaciones singulares de alteridad y dialéctica que los practicantes establecen con el medio natural, los espacios de ocio y el entorno cultural, generando disidencias y transgresiones que derivan en una "cultura deportiva" propia o adaptada (Pociello, 1999), fuera de las regularidades deportivas y turísticas convencionales (Lebreton \& Bourdeau, 2013).

El TDN es uno de los turismos específicos con mayor proyección tanto como práctica y motivación principal de algunos segmentos de demanda como desde la perspectiva de la complementariedad o motivación secundaria con otros tipos de turismo y la propia oferta de alojamiento -aun cuando no constituya muchas veces un mercado significativo por el número limitado de usuarios que aún representa en los destinos emergentes (Rivera, 2015b) - ya que enriquece el destino turístico desde un enfoque más integrador de "destino-producto" (Hinch \& Higham, 2004). Y es que del concepto de destino de los años setenta, cargado de referencias puramente geográficas y estereotipadas, se ha pasado a un concepto mucho más complejo articulado por secuencias vivenciales que éste es capaz de ofrecer a los visitantes y en el que la práctica de deportes de naturaleza se configura como uno de los productos recreativos de mayor potencial dentro de la oferta turística de no pocos destinos (Pigeassou, 1997).

\section{Turismo deportivo de naturaleza y territorio como nuevo campo de estudio de la Geografía}

El estudio de los deportes de naturaleza con orientación turístico-recreativa, por su trascendencia actual, ha despertado el interés, aunque tardía y tímidamente, de la Geografía del Turismo y del Deporte y, en menor medida, de la Geografía de la Recreación, abriendo perspectivas nuevas en el análisis de las relaciones turismo-deporte desde el enfoque espacio-temporal: los significados, la percepción y los factores de atracción de los lugares para la práctica deportiva (Bale, 2003; Lew, 2001; Hinch \& Higham, 2004), muchas veces desde la perspectiva de la geografía humanista, cultural y del comportamiento (Cloke \& Perkins, 1999); la nueva redefinición de las relaciones entre sociedad y naturaleza; las implicaciones socioeconómicas y territoriales en los destinos de turismo deportivo (Boniface \& Cooper, 1994); y el análisis de las repercusiones medioambientales, la sostenibilidad, la disponibilidad y la calidad de los recursos naturales que les sirven de soporte (Standeven \& De Knop, 1999; Lew, 2001). No obstante, la investigación geográfica en este campo adolece aún de la sistematización y consolidación de un cuerpo teórico y metodológico sólido y 
coherente (Pearce, 1995; Weed, 2006; Higham \& Hinch, 2006; Gibson, 2006), habiendo influido mucho menos que otras disciplinas como la economía, la sociología o la antropología (Butler, 2004), en parte por su relativa juventud. Y, por añadidura, las investigaciones sobre el ocio, la recreación, el turismo y el deporte se han desarrollado con frecuencia de manera independiente (Crompton \& Richardson, 1986), particularmente en la literatura anglosajona, considerando una dualidad manifiesta entre deporte y recreación pese a que sus límites se han ido haciendo cada vez más difusos y han aumentado sus convergencias e intersecciones (Bale, 1989; Pigeassou \& Filloz, 2000), de manera que sus diferencias son más bien cuestión de grado y escala (Hall \& Page, 2006, 2008).

No es extraño, por tanto, que apenas hayan generado alguna subdisciplina dentro de la Geografía, todo ello pese al creciente rol del deporte en el conjunto de las actividades culturales, económicas y de ocio de los países desarrollados, la cada vez mayor incidencia de las prácticas deportivas en la ordenación de los espacios de ocio, tanto urbanos como rurales y litorales, y la generación de una importante industria de ocio capaz de generar importantes flujos de usuarios a nivel mundial (Luque, 2012). Mientras que el deporte ha venido siendo analizado desde distintas perspectivas por disciplinas tan diversas como la psicología, la sociología, la economía o las ciencias de la actividad física y el deporte, la ciencia geográfíca ha dedicado poca atención a este fenómeno pese a su indudable dimensión territorial y estructuradora de espacios, lugares y culturas deportivas en las sociedades contemporáneas, con identidades diversas según las experiencias, tipos de práctica, percepciones y valoraciones de los usuarios y agentes implicados que han ido organizando los espacios deportivos de naturaleza (en adelante EDN) a medida de sus necesidades (Witherick \& Warn, 2003; Augustin, 2007). Ello resulta incomprensible teniendo en cuenta la potencialidad de la Geografía para la comprensión de su desarrollo reciente y sus implicaciones territoriales, medioambientales, urbanísticas o socioeconómicas. Y esto no solamente en el medio urbano, donde en principio pueden plasmarse más claramente sus efectos, sino también en el medio rural y natural, con no menos posibilidades de análisis geográfico en relación con la localización e impacto territorial de los equipamientos e infraestructuras deportivas y las nuevas actividades y prácticas de TDN, su dimensión medioambiental y su indudable interés en la planificación de nuevos modelos de desarrollo turístico sostenible (Rivera, 2015a). En este último caso, el análisis geográfico de las relaciones entre EDN y sistemas productivos locales y regionales puede ser muy útil para asegurar su funcionamiento, que ha de venir, entre otras cosas, de la interacción fructífera entre actores estructurada sobre la base de proximidades geográficas y socioeconómicas de fuerte potencial de movilización (Boutroy, Bourdeau, Mao \& Senil, 2012; Rech, Mounet \& Briot, 2009).

Los nuevos o renovados deportes de naturaleza se practican, de hecho, en muchas ocasiones en áreas naturales escasamente alteradas, lo que justifica el estudio de sus impactos y la ordenación y preservación de los recursos naturales y espacios de ocio afectados (capacidad de carga y 
acogida, redistribución locacional, evaluación de las potencialidades del medio, equipamientos e infraestructuras, etc.). Pero, además, la práctica de estas actividades presenta múltiples variaciones y perspectivas a diversas escalas, tanto en sus relaciones con el territorio como en sus variables ambientales, demográficas, sociológicas o económicas. Por tanto, el estudio de su dinámica territorial es fundamental para identificar o no la existencia de modelos espaciales y de desarrollo turístico.

En realidad, no es que se haya dado una total ausencia de la temática deportiva en los estudios geográficos (Augustin, 1995), sino que tan sólo muy tardíamente se ha prestado al tema una atención específica y estructurada en algunos países como Francia, Estados Unidos, Reino Unido o Canadá, dando lugar a una incipiente "geografía de los deportes" encuadrada dentro de la geografía cultural por algunos autores (Jesús, 1999) o casi siempre planteada en relación con los deportes convencionales de competición y de masas y la incidencia de los grandes eventos e infraestructuras deportivas en las grandes ciudades, mientras que los deportes de orientación recreativa o turística han sido muy ignorados por la Geografía, sobre todo anglosajona, pese al reconocimiento de sus especificidades espacio-temporales por parte de algunos autores (Wagner, 1981; Witherick \& Warn, 2003). Por otra parte, los deportes de naturaleza sólo han sido tratados de manera un tanto marginal y como temática secundaria dentro de la Geografía del Turismo y la Recreación, incluyendo tanto al turismo como al deporte, su asociación y sinergias mutuas, sus patrones espaciales de desarrollo y los impactos y procesos que generan en los paisajes. Y la consideración del TDN como tipología turística diferenciada sigue siendo embrionaria y limitada frecuentemente a la identificación y caracterización de los "deportes estructurantes de productos turísticos" (Kurtzman \& Zauhar, 2003).

La geografía anglosajona ha evolucionado de manera aislada, descuidando los aportes sustanciales de otros geógrafos de países como Australia, Nueva Zelanda, Sudáfrica o el Pacífico Sur, así como de la propia geografía europea (Hall \& Page, 2006), francófona (Francia, Suiza) o hispanohablante (España, Argentina, Brasil, Chile o Méjico), no siendo hasta finales de los años sesenta cuando algunos autores comienzan a aplicar sistemáticamente al deporte los métodos y herramientas de análisis geográfico (Gaffney, 2014). Como antecedentes dignos de destacar figuran la primera geografía del deporte americano de Rooney de 1974 y la primera revista de geografía del deporte de 1987 (Sport Place International); las investigaciones de Wagner en los ochenta sobre prácticas deportivas y su interrelación con el espacio social; las de la Universidad de Keele y la obra pionera Sports Geography (Bale, 1989) en Reino Unido; las contribuciones de los Congresos Nacionales de la Asociación de Geógrafos Americanos; el Atlas Americano de los Deportes de 1990 o el seminario noruego de 1994 de la Comisión de Turismo, Deporte y Ocio de la UGI.

Los primeros trabajos utilizan básicamente métodos descriptivos para localizar las actividades y equipamientos y estudiar la distribución de los usuarios y los recursos del medio físico, pero 
algunos otros también métodos cuantitativos y cartográficos para explicar los procesos de difusión espacial y evolución de las prácticas deportivas, que se verán mejorados a partir de los años noventa con los avances informáticos y estadísticos y la incorporación de nuevas dimensiones de estudio (social, cultural, histórica...). Hasta entonces la "outdoor recreation" estuvo prácticamente ausente de la geografía del deporte anglosajona y únicamente algunos geógrafos se interesaron por los deportes de naturaleza en Inglaterra y Estados Unidos en el marco de las mutaciones y conflictos recientes de los espacios rurales y la crisis de sus actividades primarias tradicionales, pero, en cuanto a objeto de investigación autónomo, han estado muy al margen de las preocupaciones dominantes de los geógrafos ingleses y americanos, como también de países europeos como España, a diferencia de lo ocurrido con los deportes tradicionales, federados, olímpicos y/o de masas.

El único país probablemente donde podemos encontrar un notable reconocimiento de la geografía del deporte en la comunidad científica es Francia, donde se ha consolidado como una subdisciplina dentro de la ciencia geográfica, contando con importante investigación especializada a partir de los años ochenta. Es el caso del Institut de Géographie Alpine de la Universidad de Grenoble I (Joseph Fourier), con sus aportaciones sobre las prácticas alpinas desde una perspectiva turística y los procesos de apropiación y construcción socioterritorial en las prácticas deportivas de naturaleza (Corneloup et al., 2004); la publicación del Atlas del Deporte de Francia de 1987 y la monografía sobre la nueva "geografía de los deportes" de la revista Mappemonde de 1985. A partir de entonces, los trabajos se han ido multiplicando y diversificando en la temática de los deportes de naturaleza y el TDN en torno a diversos focos principales: la Universidad de FrancheComté y su Centre d'Etude et de Recherche sur l'Esport et l'Observation de Territoires (CERSOT); la Universidad de Burdeos y su centro ADES (Aménagement, Dévelopment, Environment et Société), en el que destaca la figura de Augustin; la de Grenoble y su centro PACTE (Politiques Publiques, Actors Politiques, Territoire), el más especializado en la gestión e implicaciones territoriales de los deportes de naturaleza; el Grupo de Investigación "Sports, Innovation et Territoires" (SIT), vinculado a CERMOSEM (Centre d'Etudes et de Recherches sur les Montagnes Sèches et Mediterranéennes), integrado por geógrafos, economistas y sociólogos; el grupo GIREST (Groupe Interdisciplinaire de Recherche en Sport et Tourisme) de las universidades de Lille 1 y Lille 2, especializado en las relaciones deporte-turismo (Sobry, 2004). Y, por último, el Centre Interdisciplinaire Scientifique de la Montagne (CISM) de la Université de Savoie (1990); el Grupo interdisciplinar STAPS (Sciences et Téchniques des Activités Phisiques et Sportives), con diversas temáticas de interés como el geomarketing y el deporte; la asociación Reséau des Cherchers et Experts en Sports de Nature et de Montagne; y la Universidad de Pau y País de l'Adour, con sus aportaciones sobre los nuevos procesos identitarios y de relaciones sociedad-espacio generados por los deportes recreativos (Dienot \& Theiller, 1999). 
En el marco de la geografía del turismo, aunque en mucho menor grado, también se aportan desde finales de los ochenta algunos trabajos sobre prácticas deportivas de naturaleza insertos en temáticas generales sobre distribución, producción y articulación de los "sistemas turísticos" con los "sistemas locales" (Cazes, 1997). Y particularmente en la década de los noventa la geografía europea acaba por adoptar una doble perspectiva de investigación (análisis espacial de los hechos sociales y aproximación sociocultural a los hechos espaciales), empapándose de las aproximaciones sociológicas del mundo del deporte y el turismo y ampliando los puntos de mira de la geografía cultural clásica de las actividades de ocio (Augustin, 2011). El carácter exploratorio del campo de las prácticas deportivas de naturaleza desde una perspectiva geográfica no ha hecho desde entonces sino complementar las aproximaciones culturales con las socio-culturales para su mejor comprensión global.

En el ámbito hispano-luso los trabajos específicos de geografía de los deportes son, en cambio, mucho más escasos e incipientes, predominando - particularmente en España- los referidos a las actividades deportivas dentro de la vertiente de la geografía del ocio, la explotación turística, la valoración de los espacios de práctica de los deportes de naturaleza y sus implicaciones territoriales y medioambientales (Lacosta, 2002, 2004; Gómez \& Cors, 2001; Luque, 2004, 2009; Rivera, 2010). Por lo general, en las revistas más reputadas en deportes como Esporte e Sociedade (Brasil) apenas se ha dedicado atención a estas actividades y menos aún desde la perspectiva geográfica, pero encontramos algunos casos como la revista Efdeportes (Argentina) o Apunts del Deporte (España) que sí han generado estudios pioneros y de referencia desde diversas disciplinas de conocimiento, aunque también muy marginalmente desde la Geografía.

Más recientemente los deportes de naturaleza están siendo abordados por la Geografía desde una aproximación más cognitiva y partiendo de una epistemología transversal que utiliza las aportaciones de otras ciencias, sin dejar de afirmar por ello sus especificidades propias. La mayor parte de las aportaciones pueden encontrarse en revistas especializadas de carácter interdisciplinar como The Journal of Sport and Tourism, Cahiers Espaces, Téoros o Annales de Géographie y en estudios encargados por organizaciones públicas con competencias en materia de deportes, mientras que la única publicación específica de geografía del deporte que podemos reseñar es Geosport for Society, a iniciativa reciente de la Facultad de Geografía, Turismo y Deporte de Oradea (Rumanía). Pearce (1988) señala que la mayor parte de estos estudios se han limitado al estudio geográfico de los procesos de desarrollo local y regional en condiciones determinadas, como las que se han preocupado de los desarrollos costeros o del turismo de montaña, teniendo esto mucho que ver con la influencia importante de estos deportes en la emergencia, recualificación, diversificación productiva o desestacionalización de numerosos destinos. Los estudios geográficos sobre los flujos de practicantes, acciones espaciales de los operadores, tipos de desarrollo y modelo geoturístico resultante, se han venido basando en la densidad e intensidad 
de su implantación, la condición del espacio geográfico como soporte de las actividades, su momento evolutivo o fases de desarrollo en algunos destinos, la localización geográfica y emplazamiento de las actividades o la organización y ordenación espacial.

Ciertamente importante ha sido la influencia de las ciencias sociales y particularmente de la sociología o la antropología en la ciencia geográfica a la hora de comprender sistémicamente la construcción del espacio socio-cultural de los deportes de naturaleza (Pociello, 1999), sus elementos integrantes y sus interacciones, la distribución de las prácticas y de los gustos deportivos según posición social y uso del capital económico y cultural, así como el rol de los actores, individuales, colectivos o institucionales, que inciden en su estructura. Pero también hemos de considerar las aportaciones de la geografía humanista para explicar ese contexto sociocultural de las prácticas deportivas, los universos imaginarios, simbólicos y de valores o significados que los practicantes construyen individual o colectivamente de los espacios deportivos de los que se apropian (Sayeux, 2008) y las relaciones múltiples y complejas entre ellos y su medio natural y humano. Los deportes de naturaleza y aventura, como experiencias de ocio no convencionales (Dias, 2014), desafían no pocas veces los parámetros conceptuales más comunes de la definición del deporte, construyendo un imaginario y un significado social concretos, tras un proceso histórico determinado. Si el medio natural es el soporte físico y morfológico de las prácticas (montaña, paredes rocosas, nieve, pendientes, playa, olas...), los aspectos socioculturales dan "forma deportiva" a estos espacios y lugares (la pared rocosa deviene en una escuela de escalada, la pendiente se transforma en pista de esquí, la ola en un spot de surf...), co-generando formas geodeportivas múltiples (Bourdeau, Corneloup \& Mao, 2006).

No obstante, del examen de la literatura existente entendemos que sería necesario abordar con mayor dedicación las siguientes cuestiones: 1) La valoración de los flujos turísticos y de su regularidad e intensidad, así como la diversidad espacio-temporal de las prácticas y las lógicas diversas de localización, de contornos difusos, inciertos y en continua evolución (Augustin, Bourdeau \& Ravenel, 2008; Mao \& Bourdeau, 2008; Rivera, 2010); 2) La consideración de los destinos emisores como componentes de origen y desarrollo de la práctica turístico-deportiva, estudiando su interrelación con los destinos receptores; 3) la detección del significado del TDN en las nuevas estructurales territoriales de los espacios de práctica, considerando no sólo su grado de organización territorial sino también el grado de territorialidad resultante, intentando explicar los modelos espaciales de su desarrollo, así como los niveles de conflicto, yuxtaposición o complementariedad de las ADN con las actividades tradicionales en los espacios rurales y de montaña o con otras actividades turísticas o de ocio de las áreas litorales (Bourdeau, 2003); 4) el comportamiento espacial de los practicantes no sujeto a modelos positivistas y racionales y en constante interacción con el medio natural y sus cambios (Cloke \& Johnston, 2005); 5) los impactos 
territoriales y medioambientales de las actividades, la aptitud y condicionantes del espacio geográfico para su práctica y la aplicación de conocimientos geográficos para la ordenación, planificación y desarrollo sostenible del TDN (Butler \& Hall, 1998; Bourdeau, Corneloup \& Mao, 2004; Jenkins \& Pigram, 2010); y 6) la utilización de los SIGs y el geomarketing para el estudio del deporte con orientación turístico-comercial para definir estrategias de adaptación de la oferta al comportamiento espacial de los practicantes y la demanda potencial (Ravenel, 2011)

\section{La dimensión espacial de las prácticas deportivas en la naturaleza}

El espacio es un elemento indispensable para la comprensión geográfica del funcionamiento de las economías del ocio, ya que es el soporte fundamental de las actividades turístico-recreativas y también un "espacio-producto" que atrae a determinados flujos de turistas deportivos y donde se establecen unas relaciones con propiedades variables en el tiempo y en el espacio definidas por la naturaleza de las interacciones entre los recursos territoriales, los agentes humanos y sociales y las unidades espaciales a las que se dota de un sentido común. En este sentido, particularmente los geógrafos, asociando la perspectiva económica (análisis espacial y cuantitativo) con la sociocultural pueden contribuir notoriamente al análisis global e integral de las nuevas formas de espacialidad y territorialidad que dan sentido a las prácticas deportivas de naturaleza, tanto en su vertiente de ocio como de turismo (Dewailly \& Flament, 2000). Y desde la perspectiva de la investigación geográfica, el fenómeno que estudiamos puede definirse como un sistema socio-espacial integrado por unos actores, unas prácticas y unos lugares y espacios de ocio que tiene como función permitir a los practicantes realizar una actividad deportiva, lúdica y/o turística en un espacio natural.

La organización espacial del TDN, en cuanto se pone en valor tras un proceso de mercantilización de los deportes de naturaleza, se convierte en un objeto de interés geográfico con múltiples dimensiones de interés (Mao, 2003), tanto turísticas (económica, de desarrollo territorial y estructuración regional de espacios rurales y de montaña...), como lúdicas (cultural, identitaria, simbólica), deportivas y medioambientales (gestión e impacto de las actividades en los espacios naturales). Estas actividades, no obstante, presentan una clara dicotomía con los deportes tradicionales y de competición al inscribirse en lugares y formas espaciales diversas de contornos difuminados, inciertos y en continua evolución (Augustin, 2007; Augustin, Bourdeau \& Ravenel, 2008), mientras que éstos últimos se encuadran en espacios predefinidos, acotados y normalizados con infraestructuras y equipamientos específicos y proyectos territoriales de implantación pública que responden a determinados criterios demográficos, de accesibilidad o incluso turísticos (Vigneau, 2006). Esta especificidad implica, en fin, que los EDN escapen de la estandarización y del cuadro normativo y reglamentario de los lugares deportivos convencionales (Mao, 2003) y exijan un tratamiento teórico y metodológico diferenciado por parte de la Geografía. Asimismo, han de entenderse como "lugares" o "microlugares" en el sentido de las significaciones simbólicas 
y socioculturales que éstos proyectan socialmente en el contexto de los modos de aprehensión y análisis del espacio geográfico y de los procesos de territorialización y de ecogénesis territorial de las prácticas deportivas, con independencia de la diferente posición que este concepto tiene en las distintas escuelas de pensamiento anglófono, francófono o hispanohablante. De esta manera, el lugar puede adquirir diferentes formas según las lógicas, estrategias, proyectos individuales y colectivos que los actores desarrollan en el seno del espacio social, cargado de representaciones, símbolos e imaginario que trascienden el espacio meramente productivo. Los practicantes de deportes de naturaleza con orientación turístico-recreativa desean reconocerse en un territorio (spot, lugar, sitio, itinerario...) que consumen y del que se apropian y donde encuentran el medio idóneo para satisfacer su deseo de práctica deportiva, vivir determinadas experiencias, sustanciar valores y aspiraciones y establecer determinadas relaciones económicas, sociales y culturales, de manera que en los espacios y destinos de TDN interaccionan continuamente dos realidades: una física y otra humana. Y estos destinos presentan, a su vez, una gran diversidad de realidades espaciales: desde un sitio o spot puntual (una cavidad, un escarpe rocoso, una zona de oleaje...) hasta un espacio extenso (un valle, un macizo montañoso, una meseta...).

En el espacio social estos lugares son, en realidad, un sistema territorial regido por una organización integrada por actores, con unas aspiraciones, usos y proyectos individuales y colectivos que allí co-construyen mediante una dialéctica entre proximidad geográfica y proximidad organizacional que favorece la existencia de relaciones sociales y de cooperación. Y desde esta óptica de tanto interés geográfico el territorio, comprendido como un sistema social y no simplemente espacial, puede convertirse en un instrumento privilegiado para canalizar dichas relaciones (Grossetto, 2004) en el ámbito de los EDN e imprimir inteligencia territorial en los sistemas productivos locales de TDN (Bourdeau, Mao \& Corneloup, 2008).

El TDN es, por otra parte, un ejemplo antológico de cuestionamiento del modelo de difusión espacial de los polos y centros de actividad turística tradicionales, con unas peculiaridades que necesitan también de una lectura específica desde la Geografía: 1) La dispersión difusa y variabilidad espacial de las actividades que lo integran, en función del medio natural y contexto socio-cultural y la mayor individualización de las prácticas autorreguladas o autónomas, a su vez en continua transformación (Augustin, Bourdeau \& Ravenel, 2008; Rivera, 2015b); 2) La contribución de las actividades de ocio deportivas a la economía turística se opera más en el marco de un proceso de desarrollo territorial global que en el marco de una oferta estrictamente económica expresada en términos de productos; 3) Su importante impacto socioterritorial que puede ser optimizado por la implicación de las colectividades y agentes locales, así como con la puesta en marcha de un entorno cultural y un sistema de soporte adaptado al perfil de la clientela turísticodeportiva (llies, Dehoorne \& Dorina, 2014a; Falaix, 2013); y 4) Sus implicaciones en términos de sostenibilidad y compatibilización de sus prácticas con la preservación de los espacios naturales. 


\subsection{Una forma antológica de desarrollo turístico difuso}

El TDN es un caso paradigmático de "turismo difuso" (Mounet et al., 2000), presentando una clara dimensión espacial como fenómeno turístico y unas determinadas particularidades en los procesos de localización y estructuración territorial propiciados por sus flujos de turistas deportivos. En este sentido, la rareza o la abundancia de espacios deportivos similares, mercantilizados, humanizados y apropiados por diversos agentes, o la adaptación e inadaptación a la demanda recreativa y turística marcan las relaciones entre los actores de los deportes de naturaleza y sus territorios. Estos espacios, sitios o itinerarios de práctica son finalmente reconocidos por las comunidades locales como un bien de utilidad pública y adquieren un valor multifuncional desde la vertiente de la economía del ocio y el turismo, el desarrollo territorial y rural y la dinámica de los predios agrarios tradicionales, de manera que derivan en la adopción de políiticas de fomento específicas en los países y regiones con mayor desarrollo de este tipo de oferta turística.

La evolución de las prácticas se ha traducido en una notable diseminación sobre el medio natural -muchas veces lejos de núcleos urbanos y focos turísticos tradicionales- y a diferencia de los espacios deportivos "clásicos" desarrollados a partir de infraestructuras y equipamientos artificiales, configuran nuevos polos de atracción que no suelen generar centros vacacionales, estaciones turísticas o deportivas o, menos aún, complejos turístico-inmobiliarios propios del turismo de masas. Al contrario, definen una estructura de difusión multipolar, ajena a los modelos tradicionales y dominantes de localización turística polarizada propia de las estaciones turísticas y con una dinámica espacial y socieconómica inducida y una modelización geográfica más convencional. Y precisamente por ello no puede abordarse su estudio desde un análisis geográfico clásico propio de ese modelo de racionalidad espacial y geoeconómica, más propicio para los operadores turísticos, en el que existe una regla de unidad de lugar, tiempo y acción que encarna la noción de "estación turística" tematizada y monofuncional, tan asociado a los fenómenos de saturación, sobrefrecuentación y externalidades negativas del turismo de masas.

$\mathrm{Si}$ en los espacios deportivos de grandes equipamientos y zonas urbanas las localizaciones deportivas están ligadas a la distribución y proximidad de las concentraciones de población y a sus diferentes variaciones y umbrales de distancia-tiempo-coste (Ravenel, 2011), en el TDN aun cuando la demanda urbana condiciona mucho sus procesos de promoción y comercialización, dichas localizaciones están ligadas a las especificidades de los territorios y su medio físico y también a los rasgos socioculturales, surgiendo un juego de actores que condiciona la localización de la oferta y la generación de una demanda determinada, así como una importante diversificación de espacios y sitios de práctica. La demanda de las zonas urbanas fuertemente pobladas ha favorecido, como una clara ventaja competitiva, la emergencia, renovación o crecimiento de viejos y nuevos deportes 
de naturaleza, pero la disponibilidad y calidad de recursos físico-ambientales es finalmente el factor fundamental para el desarrollo, cualificación y localización de las prácticas con una relación casi estructural, particularmente en áreas periféricas y desfavorecidas, poco accesibles y lejanas de los polos demográficos y económicos pero con importantes recursos naturales. No obstante, no puede recurrirse sin algunas matizaciones a la cuestión del determinismo físico y de la lógica de causaefecto entre las condiciones geomorfológicas o naturales particulares y la localización de ciertas actividades deportivas de naturaleza más dependientes del medio natural (Mao \& Bourdeau, 2008), ya que existen otros factores que pueden condicionar también la vocación turística o deportiva de los territorios y, en cualquier caso, las distintas modalidades de práctica hacen variar la influencia físico-ambiental.

En los espacios rurales y de montaña parece existir una constante de yuxtaposición o complementariedad entre las prácticas deportivas de naturaleza y las actividades tradicionales primarias, insertándose los espacios deportivos en las márgenes, los intersticios, las fronteras o los espacios liberados por los usos agrarios ((Bourdeau, 2003; Mao \& Bourdeau, 2008). Con ello recuperan un uso, un sentido y un valor los espacios abandonados o infrautilizados marginalmente desde un punto de vista económico e incluso los que resultan poco atractivos o compatibles con las actividades turístico-recreativas contemplativas y convencionales, generando una "nueva geografía" de los espacios rurales. Más aún, si a veces las condiciones climáticas de algunos lugares han podido hacer inviable la práctica de algunos deportes, en otras ocasiones las inclemencias del medio natural han de entenderse como fortalezas y oportunidades para los deportes extremos y de aventura. En cualquier caso, hay que considerar que las posibilidades de adaptación espaciotemporal de estos deportes de naturaleza son importantes, traduciéndose en variaciones estacionales del uso de los lugares, baja intensidad de práctica en otros casos, alta movilidad de los practicantes para buscar sitios alternativos o mayor autosuficiencia de los usuarios gracias a equipos y nuevas tecnologías que mejoran los niveles de confortabilidad, seguridad y práctica.

En el TDN la referencia espacial de base se circunscribe a un sitio (un spot como se denomina en el argot deportivo), un lugar (un macizo montañoso, por ejemplo) o un itinerario (una ruta de senderismo) con unas particulares características geográficas, paisajísticas, ambientales, hidrográficas y climatológicas que determinan su aptitud como soporte de prácticas deportivas en la naturaleza: exigencias de accesibilidad, de estilo y nivel de práctica, de seguridad, de aventura y emoción, etc. Su localización, en particular, suele darse en diversas condiciones naturales poco propicias, distantes de los principales ejes de desarrollo turístico y de las aglomeraciones urbanas, de donde son mayoritariamente originarios sus practicantes. Este dominio turístico-deportivo induce, en fin, a una territorialización muy expansiva, pero también más difusa, más efímera, individualizada y permeable que los desarrollos ligados al modelo tradicional de socialización y de espacialización turística y deportiva. Así se refuerzan las nociones de multi-ubicación, multi-actividad y multi- 
territorialidad (Augustin, 2011), pasando de una espacialidad lineal y jerarquizada a otra circular y reticular en los deportes de naturaleza.

En la conformación de los EDN pueden influir, más aún que los condicionamientos físico-naturales, las condiciones y relaciones "socioculturales" (Crang, 2004): facilidad de práctica de algunos deportes, frecuentación muy estacional, flujos débiles de usuarios debido a la escasa demanda de algunas disciplinas deportivas y multiplicación de sitios de práctica; alta movilidad de los practicantes de un sitio a otro y en estancias cortas; autonomía de los profesionales del deporte; búsqueda de lugares no masificados; percepciones y representaciones psicosociales de los practicantes (Clocke \& Johnston, 2005); condiciones alojativas efímeras (vivaqueo, caravanning, tiendas de campaña...), etc. Como ocurre con algunas ofertas como los centros de turismo ecuestre (Rivera, 2010; Mao \& Bourdeau, 2008), el medio natural puede revestir un carácter secundario en su localización, aun cuando el paisaje y el medio natural pueden contribuir a la cualificación y la calidad de la prestación turístico-deportiva, de manera que responden a una lógica comercial de atención de una demanda cercana de la periferia de las grandes aglomeraciones urbanas.

Son especialmente estos condicionamientos y el propio carácter de estas actividades las que impiden en gran medida la conformación de sitios de práctica deportiva de cierta relevancia económica siguiendo el modelo de estación, centro o polo turístico centralizado y especializado, si bien pueden encontrarse algunos ejemplos como los deportes de rafting o surf, que pueden atraer importantes concentraciones de practicantes, monitores, grupos de entrenamiento, empresas comerciales de turismo activo y actividades auxiliares de restauración, alojamiento, tiendas y ocio, hasta crear un modelo de implantación espacial cercano a la estación, si bien a escalas modestas, en lugares muy demandados por sus atractivos excepcionales. La creación ex nihilo de polos turísticos basados en los deportes de naturaleza son ciertamente marginales, e igualmente ocurre con respecto a la integración y sinergias de los flujos de usuarios con centros poblacionales preexistentes, generalmente lejanos de los sitios de práctica, que suelen ubicarse (caso de los acantilados rocosos y barrancos torrenciales) en confines fronterizos, espacios marginales, improductivos y hasta repulsivos para las actividades turísticas tradicionales.

En la evolución reciente del TDN a partir de los años ochenta pueden encontrarse, no obstante, situaciones de "inconformismo" turístico y "transgresiones geodeportivas" que intentan adaptar algunas actividades deportivas a públicos amplios, hacer más accesibles algunas prácticas recreativas (periurbanas y de proximidad) o adecuarlas a los nuevos hábitos de consumo turístico, incorporando incluso a veces una lógica de artificialización que acaban por reproducir y deslocalizar determinados lugares de actividad deportiva (Bessy \& Hillairet, 2003; Vigneau, 2006). Estas situaciones han acabado por transformar algunos espacios naturales o seminaturales en verdaderos "equipamientos deportivos" más o menos blandos en la naturaleza (parques 
acrobáticos forestales y de aventura, canales artificiales de aguas bravas, vías ferrata, estaciones de vuelo libre, rocódromos, estaciones btt...), donde las prácticas ya no se encuentran tan condicionadas por el medio físico y acaban por banalizarse y democratizarse para amplias capas de población y practicantes amateurs (Bourdeau \& Mao, 2008; Rivera, 2010), acercándose incluso a las aglomeraciones urbanas como "lugares de sustitución", aun cuando el entorno ambiental siga teniendo un papel importante como soporte y cualificación de estos deportes. Y a la inversa, las prácticas deportivas más tradicionales y más ligadas al medio natural intentan amplificarse y extensificarse mediante la búsqueda de nuevos destinos de naturaleza y una mayor accesibilidad y banalización de las expediciones de aventura lejana: subida a macizos montañosos antes reservados a los alpinistas, trekking organizado por agencias especializadas, barranquismo en Madagascar, espeleología en Nueva Guinea u ofertas en destinos tan distintos como China, Méjico, Nueva Zelanda o el Cáucaso (Buckley, 2006; Millington et al., 2001). Hablar de sitio deportivo "natural" no siempre significa que los recursos de la naturaleza sean utilizados tal cual. Esto es así en los deportes aéreos y en menor medida en los deportes de aguas bravas, por ejemplo, pero no es en absoluto el caso de otros muchos deportes de naturaleza como la escalada, que exige de algún equipamiento, aunque liviano, para asegurar las rutas y preservar el entorno natural, lo que juega un papel relevante en su frecuentación (llies et al., 2014b). Las características de estos espacios pueden implicar, en efecto, niveles de equipamiento muy variables, desde un espacio natural exento de cualquier adecuación o adaptación (wilderness) donde sólo los usos y los discursos de los practicantes legitiman la actividad deportiva y el lugar, incluso hasta idealizarlo, hasta las rutas de senderismo señalizadas o los nuevos espacios innovadores, artificializados y deslocalizados (Bessy \& Hillairet, 2002), de los que hemos referido antes algunos ejemplos.

Por otra parte, las condiciones para el desarrollo y la gestión de los sitios e itinerarios de práctica se hacen cada vez más complejos para satisfacer y ampliar la demanda: procesos de tecnologización que mejoran la seguridad y accesibilidad de las prácticas (previsiones metereológicas, información geográfica a tiempo real, localizadores GPS, cobertura telefónica móvil, topoguías electrónicas, etc.); equipamiento sanitario; áreas de estacionamiento; instalación de paneles informativos, señales de balizamiento; acuerdos entre practicantes, federaciones deportivas y propietarios; alquiler o cesión de los sitios por parte de municipios o clubes deportivos; autorizaciones de uso público o de carácter medioambiental en espacios protegidos y sistema de reserva y control de aforo para grupos.

La difusión espacial de las prácticas y los niveles de frecuentación tienden a generar finalmente una fragmentación multiescalar de los espacios de ocio deportivo en función de su cercanía a los lugares de origen de los usuarios, su calidad, autenticidad natural y niveles de artificialidad que inciden en su reputación y los equipamientos de soporte que se ofrecen para las actividades, siguiendo un esquema indoor-aroundour-outdoor-wildoor, paralelo a una segmentación y 
progresión de las prácticas: ludo-deportivas, turístico-deportivas, de aventura y de deportes extremos (Mao \& Bourdeau, 2008; Bourdeau et al., 2011). El aroundoor se ubica en la zona periférica de las ciudades, estaciones turísticas y centros vacacionales, configurándose como espacio recreativo intermedio y de transición entre la artificialización total de los equipamientos deportivos y lúdicos del indoor (ciudad, estación turística, rocódromos, ...) y la "naturalidad" del outdoor (espacio natural poco artificializado), de manera que se comporta como un espacio de "iniciación" y "vulgarización" de los deportes de naturaleza, haciendo más accesibles éstos mediante adecuaciones recreativas tipo vías ferrata o parques de aventura. Mientras tanto la segmentación referida de las prácticas se articula también según esta progresión, siguiendo una diferenciación y gradación creciente según lógicas de intervención de los actores institucionales, comerciales y profesionales (equipamientos, reglamentación normativa, niveles de seguridad y accesibilidad...).

\subsection{La contribución del TDN a la economía turística y los procesos de desarrollo territorial}

El desarrollo de nuevos productos de turismo activo de naturaleza como oferta complementaria y a veces de principal motivación suele estar muy vinculado a procesos de reformulación de destinos consolidados, sobre todo de sol y playa, nieve o turismo de salud, o de creación de nuevas oportunidades de negocio, con resultados generalmente positivos en términos de oferta y de demanda. Pero también se está convirtiendo en una punta de lanza para la emergencia y la diferenciación de algunos destinos rurales, de naturaleza e interior, poco desarrollados turísticamente. La existencia, por otro lado, de unos sistemas de soporte en el territorio como las redes de senderos y vías verdes practicables, los equipamientos y adecuaciones recreativas de los Parques y Reservas Naturales o la numerosa oferta alojativa y de servicios complementarios, puede favorecer el posicionamiento y la competitividad turística de destinos con una buena climatología para el desarrollo de la mayor parte de los deportes de naturaleza.

En la actualidad la comercialización de productos turísticos relacionados con el deporte de naturaleza no llega aún a constituir un mercado muy significativo a nivel global, ya que en muchos destinos sólo atrae a un número limitado de usuarios y su impacto se visibiliza modestamente en algunos establecimientos comerciales y alojamientos de gama media o baja, si exceptuamos algunas ofertas de coaching para grupos de profesionales, algunas actividades para no iniciados en deportes como el surf, el buceo, el parapente o el rafting (los denominados "bautismos") o determinados lugares de excepcionales condiciones para su práctica. En el mercado del TDN predominan las pequeñas empresas y otros prestatarios modestos y no convencionales que ofertan actividades, frente a la escasa representación de los grandes operadores e intermediarios y las fórmulas de asociacionismo empresarial cooperativo (Corneloup, 2005; Rivera, 2015b). Por otra parte, la influencia de la localización de los sitios e itinerarios deportivos en relación con las poblaciones locales no se puede obviar, de manera que cuando la actividad turístico-deportiva 
requiere el tránsito o la estancia por una población los resultados económicos son más significativos, mientras que, por el contrario, si quedan apenas a unos cientos de metros de una vía de acceso a los espacios de práctica o de la ubicación de una zona de estacionamiento, el flujo de usuarios apenas se detecta en los pueblos y priva a éstos de beneficios económicos sensibles.

No obstante, y dependiendo de las circunstancias locales, la frecuentación de espacios de ocio deportivo en la naturaleza se está traduciendo muchas veces en aportaciones nada desdeñables en términos de diversificación de la economía local y la oferta turística, desestacionalización de la temporada tradicional, desarrollo de una oferta complementaria o alternativa a las grandes estaciones de esquí y deportes de invierno (Bourdeau et al., 2006; Rech, Mounet \& Briot, 2009; Rivera, 2011), redistribución y reequilibrio espacial de los flujos turísticos (Langenbanch, 2012) y puesta en valor de espacios naturales no integrados en la oferta turística, antes infravalorados o infrautilizados (Gómez \& Cors, 2001; Lacosta, 2002, 2004). Y en el caso de las zonas rurales y de montaña situadas lejos de los centros tradicionales de desarrollo turístico y, a veces en proceso de despoblación y crisis prolongada de sus actividades económicas tradicionales, también podemos encontrar ejemplos de dinamización de su desarrollo territorial y generación de beneficios complementarios para sus habitantes, con efectos multiplicadores de la economía local (Mao, 2003; Rivera, 2015b).

Por el hecho mismo de la dispersión geográfica de los sitios de práctica sólo se puede mantener un enfoque razonable de desarrollo turístico en la escala de pequeñas regiones en las que pueden agruparse, a su vez, múltiples spots de similares magnitudes o sitios periféricos en el entorno de un polo de atracción turístico-deportivo reputado para una determinada modalidad deportiva o para diversas disciplinas complementarias y afines. Esta estrategia refuerza obviamente la oferta turística global de los destinos por la adición y la diversificación de actividades ludodeportivas, limitando los problemas de sobrefrecuentación y saturación de zonas costeras y centros históricos, así como los efectos de la concurrencia y competencia entre sitios, además de optimizar el posicionamiento de los actores económicos involucrados. A la luz de estas consideraciones, el desarrollo de diversas formas de TDN ha de evaluarse en el marco de los imperativos de revitalización de las zonas rurales más desfavorecidas contemplados en las modernas políticas de desarrollo rural. Los esfuerzos cada vez mayores de las comunidades locales para apoyar la consolidación de estos nuevos "usos" del espacio rural adquieren hoy en día una enorme relevancia que puede relativizar y compensar la debilidad inicial que se presume de los beneficios económicos directos derivados de cada disciplina deportiva. Y esto porque se trata de fomentar una lógica de complementariedad (estacional, demográfica, económica...) entre las diferentes formas de turismo deportivo y entre éstas y otras formas de turismo (rural y cultural, de naturaleza...), ya que aquí se encuentra la clave de un desarrollo significativo, integrado, sostenible y alternativo. Por añadidura, si se gestiona correctamente el TDN también puede favorecer la revitalización de las relaciones sociales o el 
conocimiento de la realidad de las comunidades locales, a menudo tan incomprendidas desde los entornos urbanos.

No es casualidad, en fin, que el TDN está mereciendo una mayor atención desde los poderes públicos en la medida en que se trata de un subsector emergente capaz de dinamizar muchos espacios de ocio, sobre todo de interior, recualificar o consolidar otros destinos maduros como los de sol y playa o los de turismo de nieve en estaciones de esquí e incluso favorecer la imagen de "marca territorial" diferenciada de algunos destinos. Pero la intervención de las Administraciones Públicas ha de considerar las dificultades en la gestión y promoción de este segmento turístico, que han de dilucidarse partiendo de la interacción y sinergias favorables de un conjunto de parámetros: 1) la cohabitación, no siempre fácil y no exenta de conflictos de usos, entre una cultura urbana de fuerte desarrollo de los usos lúdico-deportivos y una cultura rural de transmisión, conservación y gestión de un rico patrimonio agrario, natural, paisajístico y territorial; 2) la concertación públicoprivada entre las asociaciones de conservación de la naturaleza, los clubes y federaciones deportivas, los practicantes de deportes de naturaleza y las autoridades regionales y locales con competencias en el desarrollo turístico y territorial y la conservación de los espacios naturales; y 3) la coexistencia cultural e ideológica entre la vertiente deportiva, educativa y asociativa en los sitios de práctica y la lógica profesional y comercial de los prestatarios de servicios susceptibles de posicionarse en el mercado de la pluriactividad turístico-deportiva.

El TDN puede ser una oportunidad para el desarrollo territorial sostenible (principios de equidad social y territorial, desarrollo endógeno, viabilidad económica, autonomía local y preservación de los ecosistemas), de manera que no pocos autores han calificado éste como "turismo blando", inscrito en una lógica de "auto-desarrollo" y crecimiento progresivo a partir de los propios recursos y capacidades financieras locales, principalmente, e integrado en el medio natural y social. Pero existen, en este sentido, dos puntos clave para optimizar su impacto territorial y socioeconómico: la implicación activa de las comunidades locales y la adecuación orientación del comportamiento de los practicantes. Algunos ejemplos muestran que en cuanto más están involucradas las comunidades y autoridades locales y regionales en el desarrollo del TDN y mayores sean las interacciones entre actores implicados, más eficaz se revela éste como parte de una estrategia colectiva de desarrollo (Boutroy, Bourdeau, Mao \& Senil, 2012; Rivera, 2010; Mao, 2003; Chazaud, 2004; Langenbanch, 2012; Van Lierde, 2007), favoreciendo la integración del deporte en los circuitos económicos locales, así como las sinergias entre las iniciativas individuales y públicas y la mejora de comunicación entre deportistas y operadores comerciales (Porter, 2000). Y por supuesto, es necesario también el reconocimiento mutuo entre los practicantes deportivos y la población local de acogida, evitando la ignorancia, la indiferencia o el rechazo por las molestias, falta de civismo, poco uso del comercio local o imagen negativa de los mismos entre los residentes. Parece, por tanto, fundamental que las comunidades locales se impliquen en el desarrollo del TDN 
no sólo para invertir en infraestructuras y equipamientos, sino también para reconducir las iniciativas de los operadores, ya que de lo contrario las lógicas a menudo contradictorias que son propias del turismo y el deporte prevalecerían sobre las perspectivas de desarrollo local integral. Y la superación de los factores de bloqueo o de inercia en la integración de las actividades deportivas en la economía turística pasa efectivamente por un enfoque proactivo por parte de las comunidades y los agentes institucionales y económicos interesados, con el fin de adaptarse a las necesidades específicas tan diversas de la clientela deportiva: diferente oferta de alojamiento; apertura a los modelos comerciales y relacionales propios de las culturas deportivas; toma de conciencia de la contribución potencial del turismo deportivo a las economías locales y regionales; y la apertura de las estructuras de promoción turística a la dinámica de las actividades deportivas.

Los practicantes deportivos de naturaleza tienen unos comportamientos que, en realidad, los hacen "turistas" en sí mismos aunque no lo reconozcan, pero sería imprudente no considerar las características psicosociológicas y culturales que caracterizan su forma de ser, generalmente individuales o en pequeños grupos de amigos que buscan una experiencia deportiva en un entorno natural preservado, así como su propia identidad al margen de las limitaciones sociales y económicas habituales en las zonas urbanas. Una producción turística imaginativa en torno a las actividades deportivas ha de apoyarse en la búsqueda de la autonomía, la convivencia con la población local, la sencillez de los practicantes, sus hábitos de consumo y la búsqueda de identidad que caracterizan la frecuentación de los sitios e itinerarios: el café del pueblo, la panadería, la tienda de comestibles, a menudo son lugares de referencia en la estructuración de rutas de senderistas y montañeros favoreciendo la hibridación de las funciones comerciales y sociales (búsqueda de información deportiva o general, compra de topoguías y alimentos, avituallamientos, lugar de encuentros con la gente del lugar...).

En España, por ejemplo, desde los años noventa se está valorando cada vez más la aportación y alcance de esta modalidad en la dinámica turística global, aunque ciertamente con el inconveniente de la insuficiencia y la escasa explotación específica de fuentes de información adecuadas y del escaso número de análisis de segmentación de mercados y estudios específicos a nivel nacional y regional. La atención reciente prestada en el ámbito de la promoción y el fomento del turismo y el deporte por las políticas públicas, es una prueba de confianza en este segmento como oportunidad para los destinos turísticos y por su capacidad de creación de sinergias favorables con otros segmentos de actividad (alojamientos, comercios, restaurantes, etc.), aumentando los ingresos de éstas, reforzando las señas de identidad o de marca turística de determinados territorios emergentes en turismo rural y/o de naturaleza o recualificando los destinos maduros de sol y playa. Y por ello se han puesto en marcha diversas iniciativas tendentes a la regulación, ordenación y planificación de los deportes de naturaleza como verdadero instrumento al servicio del desarrollo turístico y territorial (Chazaud, 2004; Falaix, 2013; Rivera, 2015b) y su mayor incorporación en los 
planes de promoción turística, mientras que los propios empresarios del sector turístico han comenzado a considerarlo como una faceta del turismo con una gran proyección futura.

\subsection{Deportes de naturaleza y sostenibilidad a mbiental en los espacios de ocio deportivo}

Los espacios rurales están sometidos cada vez más a procesos de urbanización y desnaturalización donde se reproducen tensiones y conflictos ligados a la protección del medioambiente y la concurrencia de diversos usos del territorio, que derivan en problemas como la banalización paisajística, la especulación inmobiliaria, el rechazo social de los actores tradicionales del medio rural (agricultores, ganaderos, cazadores, pescadores...) hacia los visitantes y el cuestionamiento del modelo de desarrollo económico y territorial no endógeno ni concertado con la población anfitriona (Beuret, 2006). El crecimiento espontáneo y desordenado, la democratización de las prácticas deportivas y la mercantilización de muchas de éstas, han tenido también que ver con ello y con la artificialización de los espacios naturales, derivando incluso en la masificación de algunos lugares, aun cuando sus impactos sean mucho menores que los provocados por otros desarrollos turísticos más duros y sus practicantes sean generalmente sensibles con el medio natural y eviten las zonas saturadas. A veces, como ya hemos comentado antes, estas prácticas han dado lugar a ciertos equipamientos y adecuaciones recreativas y a servicios de apoyo tales como alojamientos rurales y puntos de avituallamiento, que contribuyen, a través de múltiples transgresiones espaciales, territoriales y geoculturales, a la generación de un continuum creciente entre los espacios urbanos y de naturaleza. Y mientras los primeros tienden a un proceso de "naturbanización" al socaire de las nuevas tendencias en ecología urbana y de "deportivización", con equipamientos tipo rocódromos, canales fluviales, parques de aventura, carriles bici, etc. y prácticas organizadas (carreras pedestres, geocaching, nordic walking, trekking urbano...), los segundos avanzan hacia su desnaturalización por el fuerte crecimiento de estos deportes.

La extensión de la investigación geográfica a las relaciones entre las culturas deportivas, la ecología y el TDN, así como la incorporación de parámetros de sostenibilidad, se hacen muy necesarias por apoyarse estas actividades particularmente en la calidad ambiental y paisajística del entorno de prácticas, que tanto condiciona el producto final. Y tiene, asimismo, suma importancia no sólo como instrumento clave en el diseño de las consideraciones ambientales oportunas (relativas a la planificación, regulación y control y gestión y práctica de estas actividades) sino también por poder ser un buen vehículo de comunicación entre los diferentes actores implicados: federaciones y clubes deportivos, empresas prestadoras de servicios turístico-deportivos, profesionales de los deportes de naturaleza, usuarios y Administraciones Públicas. Se trata, en fin, de reflexionar sobre la eficacia de las modalidades de planificación y gestión medioambiental de los deportes de naturaleza, sobre todo en los espacios protegidos, más allá de la utilización interesada de "etiquetas verdes" en no pocas estrategias de marketing, todo esto en un momento de mayor concienciación sobre sus impactos territoriales y de mayor involucración de los poderes públicos en 
el desarrollo de instrumentos de gestión, planificación del uso público, programación de actuaciones y aseguramiento de la calidad para apoyar y ordenar el TDN.

El impacto medioambiental de los deportes de naturaleza es ciertamente difícil de caracterizar, pero ha dado lugar a una abundante literatura en la que no han faltado los geógrafos, si bien con lagunas temáticas y metodológicas importantes como el escaso tratamiento de la dinámica de las poblaciones, los aspectos ecosistémicos y la determinación de los umbrales críticos de frecuentación (Mounet et al, 2000; Luque, 2009). La consideración durante mucho tiempo de estas actividades como marginales a nivel económico no ha facilitado la financiación de programas de investigación aplicada sobre el tema en Europa y otras regiones, a diferencia de lo ocurrido en los parques naturales norteamericanos en el ámbito de la outdoor recreation (Jacob \& Schreyer, 1980; Ivy et al., 1992). Tan sólo en algunos deportes más tradicionales como el senderismo o la mountain bike se cuenta con numerosas investigaciones desde hace décadas (Farías \& Sallent, 2009), pero, en cambio, otros muchos más jóvenes apenas han sido abordados (Mounet, 2007), mientras que aspectos importantes como la capacidad de carga recreativa y los impactos, si bien están aceptablemente tratados y medidos en sitios como zonas húmedas y áreas dunares, en otros lugares siguen siendo una asignatura pendiente. A esto se suma la inercia de que los resultados obtenidos de carácter local, parciales o periódicos, caigan en afirmaciones excesivamente genéricas o incluso se transfieran acríticamente a otros espacios o ecosistemas no análogos. De esta manera, no es extraño que exista muchas veces incertidumbre y controversia sobre la determinación real de los impactos considerados como potenciales, lo que dificulta la toma de decisiones por parte de los agentes locales y poderes públicos.

Los impactos derivados de los deportes de naturaleza son, por otra parte, muy variados y versátiles y no dependen de un solo aspecto: las características intrínsecas de la actividad, modalidad y especialidad, tipo de práctica y requerimientos técnicos o forma en que son practicadas (intensidad y frecuencia, distribución temporal y espacial, grado de organización, nivel de implantación en la zona, etc.). No obstante, podemos agruparlos en cuatro categorías comunes (Mounet et al., 2000; Van Lierde, 2007): 1) El pisoteo originado tanto en los accesos a los sitios de práctica como en la realización de las actividades; 2) La perturbación de los hábitats y vida faunística en general; 3) Las afecciones a la cobertura vegetal y su composición botánica; y 4) Los impactos indirectos ligados a los accesos motorizados (parkings, circulación de vehículos, etc.), los aspectos sanitarios (basura, desechos orgánicos, contaminación del agua) y otros como el ruido y el deterioro estético de los paisajes. Algunos autores han determinado también cómo las características (número de integrantes del grupo, practicantes individuales, origen y formación), el comportamiento y la actitud medioambiental de los practicantes (aspectos conductuales) juegan un importante papel: por ejemplo, las "actividades apreciativas" de la naturaleza como el senderismo son más respetuosas que las "consumistas" como la caza y la pesca deportiva (Jackson, 1986). Y, asimismo, la 
perspectiva del análisis geográfico específico se impone a la hora de determinar y medir la capacidad de carga de los espacios de ocio (física, social y ecológica) por su diferente fragilidad o vulnerabilidad y las condiciones territoriales diversas del medio natural (plasticidad o capacidad de resiliencia, existencia o no de especies protegidas, ecosistemas especialmente sensibles), de manera que una misma actividad puede tener consecuencias diferentes en función de la capacidad de absorción del impacto de cada ecosistema y su situación de partida.

En consecuencia, la Geografía puede realizar importantes aportaciones para disponer de un nivel suficiente de conocimientos acerca de las características principales de estos impactos y plantear recomendaciones sobre las formas en que pueden ser minimizados mediante prácticas más sostenibles y ordenadas. No obstante, de la misma manera que su tratamiento diagnóstico ha de plantearse desde una visión interdisciplinar, la gestión de los espacios de ocio deportivos en la naturaleza no debe basarse de manera exclusiva, en un planteamiento de carácter ambiental, o ambientalista, dado que quien visita los mismos es un usuario que busca una experiencia turística que debería venir avalada por quienes conocen esta actividad, los gestores turísticos. Esto viene a cuento más aún considerando el carácter reciente y dinámico de muchas de estas actividades y su localización preferente en espacios naturales protegidos, lo que debería obligar a sus gestores a conocerlas y evaluarlas en sus justos términos, ordenarlas y potenciarlas racionalmente, minimizando sus impactos medioambientales pero sin caer en prohibiciones o restricciones de uso escasamente meditadas como consecuencia de una inercia proteccionista apresurada y de excesivo celo (Rivera, 2014). De esta manera, los instrumentos de evaluación ambiental han de superar la perspectiva habitual y proponer una reflexión conjunta, integral y multifacética de los problemas medioambientales entre naturalistas, científicos, federaciones deportivas, practicantes individuales, prestatarios de servicios turístico-deportivos y agentes locales, públicos y privados, ya que muchas veces son en realidad conflictos de usos relacionados con sus diferentes valores e intereses en un contexto de toma de decisiones y posiciones territoriales cada vez más complejo.

Estas actividades deportivas utilizan sitios naturales que, a su vez, soportan otras actividades humanas, ya sean productivas, residenciales, de ocio o meramente de protección de la naturaleza, pero a diferencia de éstas, y por su relativa juventud, no han estado sometidas a un marco jurídico específico. Sus especificidades e implicaciones concretas exigen que su control y tratamiento ambiental esté avalado por estudios e indicadores adecuados de sostenibilidad, evaluaciones de impacto, estudios de capacidad de carga recreativa u otros análisis específicos de carácter científico (Rivera, 2010). La complementariedad de las aproximaciones ambientalistas, geográficas y sociales es ciertamente necesaria, como también que la profundización en los conocimientos sobre protección de la naturaleza sean completados con sistemas de coordinación y concertación entre actores y se apliquen ponderadamente al ámbito de la planificación pública. Esta última puede, de hecho, facilitar las interacciones verticales y horizontales entre los agentes implicados en 
el desarrollo de estos espacios, revelándose como la mejor opción para su gestión efectiva y garantizar su calidad y sostenibilidad (Beuret, 2006; Cots et al., 2010; Rivera, 2015), aún siendo conscientes de la dificultad de establecer un proceso de democracia participativa y establecer un diálogo más objetivo y constructivo entre todos los actores implicados (Mounet, 2007). Por ejemplo, un problema específico de estos deportes es que muchos practicantes son individuales, autoorganizados, al margen de organizaciones identificables, con lo que resulta complicado implicarlos en los procesos de gestión y participación al no contar con interlocutores válidos.

En definitiva, los estudios medioambientales referidos han de ser utilizados como complemento de la concertación entre actores, partiendo de dos actitudes firmes: la gestión y planificación del territorio, los usos turístico-deportivos y los recursos basados en criterios objetivos y aplicaciones prácticas según cada caso, y la voluntad de entendimiento y comprensión mutua a partir del conocimiento y respeto de la visión de la otra parte. Y a pesar de los impactos y de que algunos practicantes ven en la naturaleza un mero "terreno de juego" sin implicación naturalista (Mounet, 2007), el TDN también puede convertirse en un importante instrumento de educación ambiental y sostenibilidad en los espacios naturales, al depender su futuro de la preservación de éstos (Kimmel, 1999), ya que muchas actividades como el senderismo incluyen el aliciente de un disfrute contemplativo, interactivo y comprensivo del entorno natural.

\section{Conclusiones}

Las prácticas turístico-deportivas de naturaleza han pasado de ser meras actividades de ocio a tener una importante dimensión económica, turística, medioambiental y hasta política, de manera que el TDN como tipología de turismo especifico emergente y diferenciada, se ha convertido incluso en un instrumento estructurador nada desdeñable de algunos territorios rurales, de montaña y litorales. Las cuestiones relativas al territorio en sentido amplio (espacios naturales, prácticas, desarrollo, infraestructuras, planificación, gestión de usos del espacio, gestión medioambiental y seguridad, gobernanza, actores, representaciones e identidades...), se muestran como más relevantes en la comprensión del TDN en la medida en que constituye el soporte y el recurso básico de la atracción y la animación deportiva, tanto para las prácticas de ocio de proximidad como para las prácticas turísticas. Por esto la Geografía ha comenzado a interesarse por este fenómeno y tiene la capacidad específica para su análisis y comprensión más integral complementando y relacionando entre sí las aportaciones de otras disciplinas de las ciencias sociales. Si hasta fechas relativamente recientes estas actividades no han llegado a reconocerse como producto turístico relevante y de identidad propia, una vez que se han ido desdibujando las fronteras tradicionalmente impermeables entre el deporte y el turismo la toma de conciencia del deporte como vector de productos turísticos ha avanzado considerablemente. No obstante, aún necesita el TDN de una reflexión geográfica sistemática articulada sobre la comprensión de su valor añadido para la oferta turística de muchos 
destinos y la explicación de su organización, pese a que reconozcamos algunos avances importantes en la literatura geográfica (Pigeassou, 2004).

La mayor parte de las ADN se caracterizan por sus entornos culturales muy específicos, en gran medida marcados por los valores identitarios de autonomía, el rechazo hacia los modelos turísticos y deportivos dominantes, el desinterés por el deporte competitivo y el consumo turístico convencional y los comportamientos atípicos, inconformistas y hasta transgresores, muy alejados de los de los consumidores turísticos "clásicos". Esta perspectiva hace necesaria una relectura de la noción de "post-turismo" (Urry, 2002; Corneloup, 2011; Bourdeau, 2003;), de manera que los deportes de naturaleza sean entendidos realmente como vectores de innovación y generadores de nuevas lógicas de desarrollo turístico (Chazaud, 2004), de una "neocultura" deportiva y territorial y ejemplo empírico de capacidad de redefinición de las fronteras, las sinergias y las conexiones de complementariedad y conflicto entre los espacios urbanos y los espacios rurales, de naturaleza y montaña (Bessy, 2010), así como de conformación y consolidación de la identidad local de algunos destinos turísticos. Y, en este sentido, no cabe duda de que la Geografía puede y debe jugar un importante papel en la explicación e interpretación de estas nuevas lógicas de tan importante componente espacial.

Los actores deportivos que impulsan estas actividades y gestionan los sitios e itinerarios de práctica se han venido preocupando básicamente por los aspectos estrictamente tecnológicos y de innovación y experiencia deportiva, al tiempo que se han despreocupado de la dimensión económica y turística de la actividad. Esto ha reforzado el aislamiento funcional y una cierta marginalidad de los deportes de naturaleza en la economía y la oferta turística de no pocos territorios, mientras que los impactos económicos, ambientales y sociales que suscita la frecuentación turístico-deportiva han acabado visualizándose incluso como mayores y más negativos que sus hipotéticos beneficios. Pero como se ha intentado plantear en este trabajo y así se ha demostrado en no pocos estudios de caso, cuando se considera aquella dimensión la dinámica resultante es ciertamente fructífera (Langenbach, 2012). Y es entonces cuando la ciencia geográfica puede aportar visiones y perspectivas útiles para explicar aspectos claves como las lógicas de localización y la organización espacial de estas prácticas, los condicionamientos del espacio geográfico, la ordenación de estas actividades en los espacios protegidos y su sostenibilidad, la caracterización de los paisajes producidos o alterados por estos deportes o la comprensión de los modelos espaciales de desarrollo y difusión del TDN, además de contribuir a la mejora de sus estrategias de promoción y comercialización de los productos turísticos que lo integran a través, por ejemplo, de las potencialidades del geomarketing. Los estudios geográficos más desarrollados están sirviendo, de hecho, para reconocer el importante potencial del TDN para la valorización de los recursos territoriales del medio natural y la sostenibilidad socioeconómica de muchos territorios, sobre todo rurales y de montaña, como también para permitir a las comunidades locales desarrollar 
el turismo valorizando las potencialidades naturales de sus territorios sin realizar inversiones costosas y acometer grandes infraestructuras o equipamientos de soporte, más aún en la medida en que su desarrollo se basa a menudo en las iniciativas de los operadores privados, cuyo número tiende a multiplicarse cada vez más.

En el nivel teórico y metodológico, la ciencia geográfica puede interpretar también mejor que otras disciplinas el carácter singular y predominantemente "difuso" del modelo de implantación espacial del TDN, que va en contra de los modelos dominantes de la geoeconomía del turismo y no responde a los criterios de centralidad, polaridad y accesibilidad que condicionan la integración exitosa de la frecuentación turístico-deportiva en el desarrollo territorial. No obstante, la Geografía ha de avanzar aún mucho en el análisis de este fenómeno y particularmente en cuestiones básicas como: 1) la medición y observación de los flujos de frecuentación y su caracterización espaciotemporal, incluyendo imperativamente opciones y ajustes diversos en función de las especificidades de cada cultura deportiva (multiplicidad y heterogeneidad de prácticas) y cada zona geográfica (espacios de ocio variados); 2) la necesaria visión inductiva y cruzada de los ejes de desarrollo del TDN, sus impactos territoriales y sus modos de diversificación e interacción con otros subsectores turísticos o de ocio; 3) los proyectos territoriales relacionados con las ADN (gestión intercomunitaria del deporte, transformación de espacios de ocio deportivo en destinos turísticos de manera sostenible, clusters regionales de innovación deportiva, planificación de equipamientos e infraestructuras de soporte...; 4) la determinación de las nuevas relaciones teóricas entre representaciones, culturas e identidades deportivas o entre especialidades, desarrollo local y gobernanza, en el ámbito de los deportes de naturaleza y su inserción en las dinámicas contemporáneas globales (Augustin, 2007, 2011); 5.) la mayor integración en las reflexiones de la Geografía sobre este fenómeno de las aportaciones teóricas y metodológicas de otras ciencias sociales y particularmente la sociología, la psicología, la economía o la antropología, todo ello a favor de una visión más integral del fenómeno y una geografía más cognitiva y fenomenológica, atenta no sólo a las aptitudes y condicionamientos del medio natural sino también a las actitudes y comportamientos de los grupos humanos en el espacio, o sea, una geografía de los "espacios vividos" y percibidos; y 6) la determinación de modelos geográficos y económicos con una orientación aplicada que permitan predecir los escenarios y los lugares más ideales para el desarrollo de este fenómeno y la minimización de sus impactos negativos en todos los órdenes (Gaffney, 2014).

Declaración responsable: Las/os autoras/es declaran que no existe ningún conflicto de interés en relación a la publicación de este artículo. 


\section{Bibliografía}

Augustin, J. P. (1995). Sport, géographie et aménagement. Paris: Nathan.

Augustin, J.P. (2000). Activités ludo-sportives et médiations territoriales. Montagnes Mediterranéennes, 11, 29-52.

Augustin, J.P. (2007). Géographie du Sport. Spatialités contemporaines et mundialisation. Paris: Armand Colin.

Augustin, J. P. (2011). Qu'est-ce que le sport? Cultures sportives et Géographie. Annales de Géographie, 170(680), 361-382.

Augustin, J. P., Bordeaux, P., \& Ravenel, L. (2008). Géographie des sports en France. Paris: Vuibert.

Bale, J. (2003). Sports geography. New York: Routledge.

Bell, S., Tyrväinen, L., Sievänen, T., Pröbstl, U. \& Simpson, M. (2007). Outdoor recreation and Nature Tourism: A European Perspective. Living Revue Landscape Research, 1(2), 1-46.

Bessy, O. (2010). Les loisirs sportifs de nature, vecteurs de renouvellement des contours du tourisme. Sud-ouest Européen, 29, 105-114.

Bessy, O., \& Hillairet, D. (2003). Les espaces sportifs innovants. Voiron: Presses Universitaires du Sport.

Bessy, O., \& Mouton, M. (2004). Du plein air au sport de nature. Nouvelles pratiques, nouveaux enjeux. Cahiers Espaces, 81, 13-29.

Beuret, J. E. (2006). La conduite de la concertation pour la gestion de l'environnement et le partage de ressources. Paris: L'Harmattan.

Boniface, B. G., \& Cooper, C. (1994). The geography of travel and tourism. Oxford: ButterworthHeinemann.

Bouchet, P., \& Bouhaouala, M. (2009). Tourisme sportif. Un essai de definition socio-économique. Téoros, 28(2), 3-8.

Bourdeau, P. (2003). Territoires du hors-quotidien. Le cas du tourism sportif de montagne et de nature (Doctoral dissertation, University Joseph Fourier, France).

Bourdeau, P., Corneloup, J., \& Mao, P. (2004). Outdoor sports and tourism in the French mountains: towards a sustainable development? In B. W. Ritchie, \& D. Adair (Coords.), Sport Tourism: Interrelationships, Impacts and Issues (pp. 101-116). Clevedon: Channel View Publications. 
Bourdeau P., Corneloup, J., \& Mao, P. (2006). Cultures, espaces et métiers sportifs de la montagne: changements et enjeux d'avenir. In P. Bordeau (Dir.), La montagne comme terrain de jeu et d'enjeux (pp. 11-28). L'Argentière: Editions du Fournel.

Bourdeau, P., \& Mao, P. (2008). La diversité et la spécificité géographique des sports de nature. In J. P. Augustin, P. Bourdeau, \& L. Ravenel (Coords.), Géographie des sports en France (pp. 121139). Paris: Vuibert.

Bourdeau, P., Pascal, M., \& Corneloup, J. (2011). Les sports de nature comme médiateurs du "pas de deux" ville-montagne. Une habitabilité en devenir? Annales de géographie, 4(680), 449-460.

Boutroy, E., Bourdeau, P., Mao, P., \& Senil, N. (2012). Combinaison de proximités géographiques et socioéconomiques: la filiére tourisme sportif de montagne et de nature en Rhône Alpes. Revue de Géographie Alpine, 100(3). Retrieved from http://rga.revues.org/1890

Brown, M. (2009). Reconceptualising outdoor adventure education. Australian Journal of Outdoor Education, 13(2), 3-13.

Buckley, R. (2006). Adventure Tourism. Australia: Griffith University \& ICER.

Buckley, R. (2007). Adventure tourism products: price, duration, size, skill, remoteness. Tourism Management, 28, 428-433.

Butler, R. (2004). Geographical research on tourism, recreation and leisure: origins, eras and directions. Tourism Geographies, 6(2), 143-162.

Butler, R., \& Hall, C. M. (1998). Rural recreation and tourism. In B. Ilbery (Dir.), The Geography of Rural Change (pp. 21-32). Harlow: Addison Wesley Longmen.

Cazes, G. (1997). La géographie du tourisme: reflexión sur les objectifs, et les pratiques en France. Annales de Géographie, 537, 595-600.

Chang, S., \& Gibson, H. (2011). Physically Active Leisure and Tourism Connection. Leisure Sciences, 33, 162-181.

Cloke, P., \& Johnston, R. (2005). Spaces of Geographical thought. London: Sage.

Cloke, P., \& Perkins, H. (1999). Cracking the canyon with the awesome foursome: representations of adventure tourism in New Zealand. Environment and Planning: Society and Space, 16, 185218.

Cots, F., Roca, E., Baeza, L., \& Sallent, O. (2010). Turismo activo y sostenibilidad en Cataluña. Estudios Turísticos, 183, 73-90.

Corneloup, J. (2005). La place du marché dans le fonctionnement des loisirs sportifs de nature. Téoros, 24(1), 55-61. 
Corneloup, J. (2011). La forme transmoderne des pratiques récréatives de nature. Développement durable et territoires, 2(3), 1-19.

Corneloup, J., Bourdeau, P., Mao, P., \& Boutroy, E. (2004). Cultures sportives de nature et territoires: un état des lieux de la recherche française depuis 1990. Cahiers de la Géographie du Québec, 48(133), 33-46.

Chazaud, P. (2004). Management du tourisme et des loisirs sportifs de pleine nature. Voiron: Presses Universitaires du Sport.

Crompton, J., \& Richardson, S. (1986). The tourism connection where public and private leisure services merge. Parks and Recreation, 67, 38-44.

Dewailly, J. M., \& Flament, E. (2000). Le tourisme. Paris: SEDES.

De Knop, P. (1990). Sport for all and active tourism. World Leisure and Recreation, 32, 30-36.

Días, C. (2014). Sport and Environment in Brazil: A Historical Overview. The International Journal of the History of Sport, 37(10), 1255-1266.

Dienot, J., \& Theiller, D. (1999). Les nouveaux loisirs sportifs en montagne: les aventuriers du quotidian. Pau: Maison des Sciences de l'Homme d'Aquitaine.

Falaix, L. (2013). Sports de nature: jeux d'acteurs institutionnels et gouvernance territoriales. Espaces, Tourisme et Loisirs, 313, 4-9.

Falaix, L. (2015). Sports de nature et decentralization. Développement durable et territoires, 6(1). doi: $10.4000 /$ developpementdurable. 10820

Gaffney, C. (2014). Geography of sport. In J. A. Maguire (Ed.), Social Sciences in Sport (pp. 109-134). Champaing: Human Kinetics.

Gammon, S., \& Robinson, T. (2003). Sport and tourism: A conceptual framework. Journal of Sport\&Tourism, 8(1), 21-26.

Giard, D. (1997). Les enjeux du tourisme sportif en montagne. Cahiers Espace, 52, 53-63.

Gibson, H. J. (2006). Sport Tourism: Concepts and Theorie. Oxon: Routledge.

Gómez, B., \& Cors, M. (2001). Los deportes de aventura en el Pallars Sobirá. In Rodríguez, F. (Coord.), Actas del XVII Congreso de la Asociación de Geógrafos Españoles (pp. 335-339). Oviedo: Universidad de Oviedo y Asociación de Geógrafos Españoles.

Grossetti, M. (2004). Concentration d'enterprises et innovation: ésquisse d'une typologie des systems productifs locaux. Géographie, économie, société, 6(2), 163-177.

Hall, C. M., \& Page, S. (2006). The Geography of Tourism and Recreation. New York: Routledge. 
Higham, J., \& Hinch, T. D. (2006). Sport and Tourism Research: A Geographic Approach. Journal of Sport \& Tourism, 11(1), 31-49.

Hinch, T. D., \& Higham, J. (2004). Sport tourism development. Clevedon: Channel View.

Ilies, A., Dehoorne, O., Wendt, J., \& Kozma, G. (2014a). For Geography and Sport, Sport Geography or Geography of Sport. Geosport for Society, 1(1-2), 7-18.

Ilieș, A., Dumitrescu, G., Dragoș, P., Buhaș, S. (2014b). Sport, infrastructure and sport activitiestourist ressources. In llieș, A. (Ed.), Crișana-Maramuneș. Geographical Atlas of Tourist Patrimony (pp. 280-285). Oradea: Editura Universității din Oradea.

Ivy, M. I., Stewart, W. P., \& Lue, C. C. (1992). Exploring the role of tolerance in recreational conflict. Journal of Leisure Research, 24(4), 348-360.

Jackson, E. L. (1986). Outdoor recreation: participation and attitudes to the environment. Leisure Studies, 5, 1-23.

Jacob, G. R., \& Schreyer, R. (1980). Conflict in outdoor recreation: a theoretical perspective. Journal of Leisure Research, 12(4), 368-380.

Jenkins, J. M., \& Pigram, J. (2010). Outdoor recreation management. Chongging: University of Chongging.

Jesús, G. M. (1999). A Geografia dos sportes. Uma introduçao. Scripta Nova, 35. Retrieved from hitp://www.ub.edu/geocrit/sn-35.htm

Kimmel, J. R. (1989). Ecotourism as Environmental Learning. The Journal of Environmental Education, 30(2), 40-44.

Kurtzman, J., \& Zahuar, J. (2005). Sports tourism consumer motivation. Journal of Sport Tourism, 10, 21-31.

Lacosta, A. J. (2002). Los deportes de aventura y su incidencia en el desarrollo turístico de un espacio protegido: el PN Cañones y Sierra de Guara (Huesca). In Turismo y transformaciones urbanas en el siglo XXI (pp. 233-247). Almería: Asociación de Geógrafos Españoles.

Lacosta, A. J. (2004). La configuración de nuevos destinos turísticos de interior en España a partir del turismo activo y de aventura (1992-2001). Cuadernos Geográficos, 34, 11-32.

Langenbanch, H. (2012). Le marché du tourisme sportif de nature dans les systems territoriaux des espaces touristiques et ruraux (Doctoral dissertation, University of Grenoble, France). 
Lebreton, F., \& Bourdeau, P. (2013). Les dissidences récréatives en nature: entre jeu et transgression. EspacesTemps.net. Retrieved from https://www.espacestemps.net/articles/lesdissidences-recreatives-en-nature-entre-jeu-et-transgression/

Lew, A.A. (2001). Tourism and geography space. Tourism Geographies, 3(1), 7-11.

Loret, A. (1995). Génération glisse, dans l'eau, l'air, la neige... Paris: Autrement.

Luque, A.M. (2004). Factores de localización espacial para actividades turístico-deportivas en la naturaleza. Málaga: Universidad de Málaga.

Luque, A.M. (2012). El deporte como objeto de reflexión e investigación geográfica. Boletín Asociación de Geógrafos Españoles, 59, 49-77.

Mao, P. (2003). Les lieux de pratiques sportives de nature dans les espaces ruraux et montagnards (Doctoral dissertation, University Joseph Fourier, France).

Mao, P., \& Bourdeau, P. (2008). Les lieux de pratique des sports de nature en France: une géographie differenciée. Mappemonde, 89. Retrieved from http://mappemonde.mgm.fr/num17

Millington, K.; Locke, T. Y Locke, A. (2001). Occasional studies: adventure travel. Travel and Tourism Analyst, 4, 65-97.

Mounet, J. P., Rocheblave, M., \& Nicollet, J. P. (2000). L'impact des activités sportives de nature sur l'environnement naturel. Montagnes Méditerranéennes, 11, 67-76.

Mounet, J. P. (2007). Sports de nature, développement durable et controverse environnementale.

Natures Sciencies Sociétés, 15(2), 162-166.

Parlebas, P. (1999). Jeux, sports et sociétés. Paris: INSEP.

Pearce, D. G. (1995). Tourism today: a geographical analysis. Harlow: Langman.

Pigeassou, C. (1997). Sport and tourism. Journal of Sport Tourism, 4(2), 20-38.

Pigeassou, C. (2004). Le tourisme sportif: une réalité sociale aux contours entertains. In Y. Sobry (Dir.), Le Tourisme sportif (pp. 33-71). Vileuneuve d'Asq: Septentrion.

Pigeassou, C., \& Filloz, V. (2000). Du tourisme sportif au sport touristique. Cahiers Espaces, 66, 92-94.

Pociello, C. (1999). Sports et sciences sociales. Paris: Vigot.

Porter, M. (2000). Location clusters company strategy. In G. I. Clark et al (Coords.), The Oxford Handbook of Economic Geography (pp. 253-274). Oxford: Oxford University Press.

Ravenel, L. (2011). Une approche géomarketing du sport. Annales de Géographie, 4(680), 383404. 
Rech, Y., Mounet, J. P., \& Briot, M. (2009). L'innovation dans les sports de nature: I'irruption de nouvelles activités dans une station de sports d'hiver. Espaces \& Sociétés, 136-137, 157-171.

Rivera, M. (2010). Turismo activo en la naturaleza y espacios de ocio en Andalucía. Sevilla: Consejería de Turismo y Comercio, Junta de Andalucía.

Rivera, M. (2015a). El tratamiento de las actividades de turismo activo en los instrumentos de planificación ambiental de los PN andaluces. Estudios Regionales, 102, 17-63.

Rivera, M. (2015b). La oferta comercial de turismo activo de naturaleza en España: estructuración, tendencias y contexto territorial. Turismo y Sociedad, 16, 85-108.

Sobry, C. (2004). Le tourism sportif. Villeneuve d'Ascq: Septentrion.

Standeven, J., \& De Knop, P. (1999). Sport Tourism. Champaign, IL: Human Kinetics.

Urry, J. (2002). The Tourist Gaze. London: Sage Publications.

Van Lierde, N. (2007). Sports de nature, outils pratiques pour leur gestion. Paris: L'Atelier.

Vigneau, F. (2006). Espaces du sport et aménagement sportif des territoires (Doctoral dissertation, Université Toulouse II-Le Mirail).

Wagner, P.L. (1981). Sport: culture and geography. In R. Allan (Dir.), Space and time in Geography (pp. 85-108). Lundm: Gleerup.

Weed, M. (2006). Sport tourism research 2000-2004: A systematic review of knowledge and meta-evaluation of methods. Journal of Sport Tourism, 11(1), 5-30.

Witherick, M., \& Warn, S. (2003). The Geography of Sport and Leisure. Cheltenham: Nelson Thornes Ltd. 